\title{
Bronchoalveolar lavage under ultrasound monitoring of lungs for the treatment of neonatal atelectasis and lung consolidation
}

\author{
FENG ZAILI $^{1,2}$ and YIN ZHAOQING ${ }^{2}$ \\ ${ }^{1}$ Department of Neonatology, Kunming Medical University, Kunming, Yunnan 650500; \\ ${ }^{2}$ Department of Neonatology, Dehong People's Hospital, Mangshi, Yunnan 678400, P.R. China
}

Received January 22, 2021; Accepted May 20, 2021

DOI: $10.3892 /$ wasj.2021.111

\begin{abstract}
Neonatal atelectasis and pulmonary consolidation diseases are common and difficult to treat. Thus, novel treatment methods need to be explored. Although an X-ray chest radiography is feasible for the detection of neonatal atelectasis and pulmonary consolidation diseases, there is a risk of radiation damage and lung ultrasound may be used instead. The aim of the present study was to investigate the bronchoalveolar lavage (BAL) under ultrasound monitoring of lungs for the treatment of neonatal atelectasis and lung consolidation disease. For this purpose, the present study prospectively selected 73 children with severe newborn respiratory distress syndrome (NRDS), 60 children with severe neonatal pneumonia (NP), and 65 children with meconium aspiration syndrome (MAS) as the research subjects. Each disease was divided into three groups as follows: The exogenous pulmonary surfactant (PS) lavage group, the normal saline (NS) lavage group and the non-lavage group, using lung ultrasound as the imaging method for lung disease. The treatment effect, complications and differences in the oxygenation index (OI) among the three groups of each disease were compared. The results revealed that the time of lung recruitment and invasive ventilator treatment among the three groups of each disease was shorter in the PS lavage group than in the NS lavage
\end{abstract}

Correspondence to: Professor Feng Zaili, Department of Neonatology, Kunming Medical University, 1168 Chunrong West Road, Yuhua Street, Chenggong, Kunming, Yunnan 650500, P.R. China

E-mail: fengzaili@sina.com; 1007363616@qq.com

Abbreviations: BAL, bronchoalveolar lavage; NRDS, newborn respiratory distress syndrome; NP, neonatal pneumonia; MAS, meconium aspiration syndrome; OI, oxygenation index; PS, pulmonary surfactant; NS, normal saline; NICU, neonatal intensive care unit; INO, inhaled nitric oxide; CRRT, continuous renal replacement therapy; CDFI, color doppler flow imaging; HPA axis, hypothalamicpituitary-adrenal axis; $\mathrm{FiO}_{2}$, fraction of inspired $\mathrm{O}_{2}$; MAP, mean airway pressure; $\mathrm{PaO}_{2}$, arterial oxygen partial pressure; $\mathrm{SpO}_{2}$, oxygen saturation

Key words: infant, newborn, atelectasis, lung consolidation, alveolar lavage, lung ultrasound, monitoring group, and also between the PS lavage and NS lavage group compared with the non-lavage group $(\mathrm{P}<0.05)$. Following treatment for each disease, the PS lavage group exhibited a more rapid decline in OI than the NS lavage group, and the PS lavage group and NS lavage group exhibited a more rapid decline in OI than the non-lavage group $(\mathrm{P}<0.05)$. No significant differences in treatment complications were observed among the three groups of each disease $(\mathrm{P}>0.05)$. On the whole, the present study demonstrates that BAL under lung ultrasound monitoring is effective in the treatment of neonatal atelectasis and pulmonary consolidation diseases caused by severe NRDS, severe NP or MAS. It can decrease the invasive ventilator treatment time of neonatal atelectasis and lung consolidation more rapidly, and can rapidly decrease the OI, without increasing complications. Thus, exogenous PS lavage is more effective than NS lavage.

\section{Introduction}

Neonatal lung ultrasound images of severe newborn respiratory distress syndrome (NRDS), severe neonatal pneumonia (NP) and meconium aspiration syndrome (MAS) mainly reveal atelectasis and lung consolidation, and it is difficult to distinguish these diseases based on the performance of lung ultrasound alone $(1,2)$. Neonatal atelectasis and lung consolidation are common complications of severe NRDS, severe NP and MAS. The purpose of treatment is lung recruitment. An $\mathrm{X}$-ray chest radiography is typically conducted to determine whether the lung has been recruited again; however, there is a risk of radiation damage. Therefore, a clinical evaluation technique without the risk of radiation damage is required $(1,3-5)$. In recent years, some scholars have proposed the use of lung ultrasound to examine lung diseases (6-10). The treatment of neonatal atelectasis and lung consolidation diseases is difficult, and novel treatment methods thus need to be explored. Bronchoalveolar lavage (BAL) is known to be effective in the treatment of neonatal atelectasis and lung consolidation diseases; however, available related studies are limited $(11,12)$. To the best of our knowledge, to date there is no comprehensive study of BAL in the treatment of severe NRDS, severe NP and MAS. Therefore, the present prospective study aimed to provide a reference for the clinical application of BAL in the treatment of neonatal atelectasis and lung consolidation diseases under lung ultrasound monitoring. 


\section{Patients and methods}

Patients. The present prospective study was conducted at the Level 3 neonatal intensive care unit (NICU) of the Department of Neonatology, Kunming Medical University, Kunming, China. The study was approved by the Medical Ethics Committee of the Dehong People's Hospital Affiliated to Kunming Medical University, and signed informed consent was obtained from the guardians of the children. The research subjects included 73 cases of severe NRDS, 60 cases of severe $\mathrm{NP}$ and 65 cases of MAS admitted to the Level 3 NICU of the Department of Neonatology, Kunming Medical University between March, 2018 and December, 2020. Lung ultrasound was used as the imaging method for lung disease (Table I).

Diagnosis and treatment. Disease diagnosis, treatment, initial parameter setting of invasive mechanical ventilation, adjustment during treatment, invasive mechanical ventilation combined with inhaled nitric oxide (INO) treatment, continuous renal replacement therapy (CRRT) and the application of exogenous pulmonary surfactant (PS) (PS for Poractant Alfa Injection, Chiesi Farmaceutici S.p.A.) were all based on the published guidelines and 'Pediatric mechanical ventilation' $(1,7,13,14)$.

Inclusion and exclusion criteria. The inclusion criteria were the following: For severe NRDS: i) An age $<12$ h; ii) invasive mechanical ventilation-assisted ventilation was required; iii) atelectasis, lung consolidation $\geq 2$ intercostal spaces; iv) diagnosis of severe NRDS. For severe NP: i) An age $\leq 28$ days; ii) invasive mechanical ventilation-assisted ventilation was required; iii) atelectasis, lung consolidation $\geq 2$ intercostal spaces; iv) diagnosis of severe NP. For MAS: i) An age $<24$ h; ii) invasive mechanical ventilation-assisted ventilation was required; iii) atelectasis, lung consolidation $\geq 2$ intercostal spaces; iv) diagnosis of MAS. The exclusion criteria were as follows: i) Complicated with congenital heart disease; ii) grade III-IV intracranial hemorrhage; iii) diaphragmatic hernia, swollen diaphragm; iv) hemophilia, VitK1 deficiency; v) lung isolation syndrome; vi) pulmonary hemorrhage.

Research methods and observation. An ultrasonic examination of the neonatal lungs was conducted using probes with a frequency of $5-15 \mathrm{MHz}$, with $>9.0 \mathrm{MHz}$ being more commonly used $(15,16)$. Infected patients were treated with sensitive antibiotics, severe renal impairment was treated with CRRT, and those with concomitant persistent pulmonary hypertension of the newborn (PPHN) were treated with a combination of inhaled nitric oxide (INO) (17). The lavage method invovled the following procedures: i) Complete tracheal intubation before lavage, and fully remove meconium before lavage for MAS; ii) the PS lavage group was irrigated twice with normal saline (NS) at $1.5 \mathrm{ml}$ for premature infants, NS at $3 \mathrm{ml}$ for full-term infants, and the third lavage with exogenous PS $50 \mathrm{mg} / \mathrm{kg}+\mathrm{NS}$; NS capacity $(\mathrm{ml})$ is the same as PS calculation capacity (ml); the NS lavage group was irrigated three times with NS alone $1.5 \mathrm{ml}$ for premature infants, NS $3 \mathrm{ml}$ for full-term infants; iii) balloon-connected tracheal tube ventilation or mechanical ventilation higher than the normal $2 \mathrm{cmH}_{2} \mathrm{O}$ peak inspiratory pressure (PIP) was administered for 2-5 min following the injection of lavage fluid (18); iv) the vital signs of the child were monitored throughout the lavage; it was ensured that the child exhibited no hypoxia during lavage; v) efforts were made to ensure the quality of the lavage, but also to ensure the operation was performed in a skilled and sensitive manner. For PS treatment after lavage, an intratracheal infusion of $100 \mathrm{mg} / \mathrm{kg}$ of exogenous PS was administered within 10 min following alveolar lavage. The non-lavage group was directly administered exogenous PS at $100 \mathrm{mg} / \mathrm{kg}$ via intratracheal instillation. Treatment follow-up and PS application involved the following: i) Lung recruitment index: The range and extent of atelectasis and lung consolidation as revealed by the lung ultrasound image were reduced; ii) lung ultrasound was reviewed $2-4 \mathrm{~h}$ following lavage to monitor lung recruitment; when there was no obvious lung recruitment in $24 \mathrm{~h}$, a second infusion of exogenous PS at $100 \mathrm{mg} / \mathrm{kg}$ was administered via intratracheal instillation. When there was no obvious lung recruitment in $48 \mathrm{~h}$, a third infusion of exogenous PS at $100 \mathrm{mg} / \mathrm{kg}$ was administered via intratracheal instillation. The indications for the withdrawal of the invasive ventilator were the following: i) The cause of respiratory failure had been relieved or was being relieved; ii) the airway was unobstructed, the cough reflex was obvious, and the strength of the respiratory muscles was restored; spontaneous breathing was strong (active), with sputum suction tolerance; iii) the ventilator parameters were already low: Fraction of inspired $\mathrm{O}_{2}\left(\mathrm{FiO}_{2}\right)<40 \%$, respiratory rate (RR) $<15$ beats/min, PIP $<15 \mathrm{cmH}_{2} \mathrm{O}$, positive end-expiratory pressure (PEEP) $<4 \mathrm{cmH}_{2} \mathrm{O}$ and arterial blood gas analysis was normal; iv) under lower ventilator parameters the lung ultrasound examination prompted two consecutive times to indicate that the lung had been recruited, and the interval between the two examinations was $\geq 4 \mathrm{~h}$; v) the circulatory state was stable and did not rely on circulating drugs; vi) no muscle relaxants were within $12 \mathrm{~h}$. The aforementioned conditions had to be met simultaneously in order invasive ventilator therapy to be withdrawn. For observations and comparisons, the differences in treatment effects, complications and the oxygenation index (OI) among the three groups for each disease.

Statistical analysis. The data were analyzed using SPSS 25.0 software (SPSS, Inc.), and the measurement data that conformed to the normal distribution are expressed as the mean \pm standard deviation (mean $\pm \mathrm{SD}$ ). Comparisons among multiple groups were performed using one-way ANOVA., and with the least significant difference (LSD) post hoc test. Count data are expressed as a percentage; significant differences in rates were tested using a Chi-squared test or Fisher's exact probability test. A P-value $<0.05$ was considered to indicate a statistically significant difference.

\section{Results}

No statistically significant differences were found in the general data among the three groups $(\mathrm{P}>0.05)$ (Table I), comparable among the three groups. The difference in lung recruitment time and invasive ventilator treatment time among the three groups was statistically significant $(\mathrm{P}<0.05)$. The PS lavage group exhibited a shorter time than the NS lavage group, and the PS lavage group and NS lavage group exhibited 
Table I. Comparison of general information of the three groups.

\begin{tabular}{|c|c|c|c|c|c|}
\hline Group & PS lavage group & NS lavage group & No lavage group & $\mathrm{F} / \chi^{2}$ value & P-value \\
\hline Severe NRDS & 22 & 24 & 27 & & \\
\hline Male & 12 & 11 & 14 & 0.37 & $>0.05$ \\
\hline Gestational week & $30.77 \pm 2.47$ & $30.55 \pm 2.58$ & $31.29 \pm 3.45$ & 0.4391 & $>0.05$ \\
\hline Birth weight (kg) & $1.587 \pm 0.539$ & $1.667 \pm 0.439$ & $1.727 \pm 0.486$ & 0.499 & $>0.05$ \\
\hline Age (min) & $45.62 \pm 25.27$ & $42.62 \pm 25.27$ & $50.62 \pm 25.27$ & 0.6551 & $>0.05$ \\
\hline Cesarean section & 7 & 9 & 10 & 0.20 & $>0.05$ \\
\hline PS use times & $1.14 \pm 0.47$ & $1.12 \pm 0.45$ & $1.30 \pm 0.54$ & 1.0344 & $>0.05$ \\
\hline Combined INO treatment & 3 & 4 & 5 & 0.21 & $>0.05$ \\
\hline CRRT & 1 & 0 & 1 & 10.40 & $>0.05$ \\
\hline Severe NP & 19 & 21 & 20 & & \\
\hline Male & 10 & 9 & 9 & 0.42 & $>0.05$ \\
\hline Gestational week & $39.26 \pm 2.07$ & $39.64 \pm 2.57$ & $40.16 \pm 2.87$ & 0.6221 & $>0.05$ \\
\hline Birth weight (kg) & $2.98 \pm 0.77$ & $3.03 \pm 0.66$ & $3.18 \pm 0.43$ & 0.5321 & $>0.05$ \\
\hline Age (days) & $13.91 \pm 5.02$ & $14.51 \pm 4.92$ & $14.88 \pm 4.88$ & 0.1909 & $>0.05$ \\
\hline $\begin{array}{l}\text { Maternal infection } \\
\text { during delivery }\end{array}$ & 3 & 1 & 3 & 1.50 & $>0.05$ \\
\hline PS use times & $1.11 \pm 0.32$ & $1.10 \pm 0.30$ & $1.40 \pm 0.68$ & 2.6675 & $>0.05$ \\
\hline Combined INO treatment & 1 & 1 & 2 & 0.54 & $>0.05$ \\
\hline CRRT & 1 & 1 & 2 & 0.54 & $>0.05$ \\
\hline MAS & 20 & 21 & 24 & & \\
\hline Male & 13 & 11 & 12 & 1.11 & $>0.05$ \\
\hline Gestational week & $40.1 \pm 1.64$ & $40.9 \pm 1.84$ & $41.1 \pm 1.24$ & 2.3786 & $>0.05$ \\
\hline Birth weight (kg) & $3.951 \pm 0.357$ & $3.808 \pm 0.355$ & $4.022 \pm 0.214$ & 2.7118 & $>0.05$ \\
\hline Age (h) & $5.30 \pm 1.52$ & $4.41 \pm 2.51$ & $5.79 \pm 1.95$ & 2.6088 & $>0.05$ \\
\hline PS use times & $1.60 \pm 0.82$ & $1.62 \pm 0.86$ & $1.75 \pm 0.90$ & 0.2012 & $>0.05$ \\
\hline Combined INO treatment & 3 & 3 & 4 & 0.05 & $>0.05$ \\
\hline CRRT & 0 & 0 & 0 & & $>0.05$ \\
\hline
\end{tabular}

No significant differences were observed between any of the groups. NRDS, newborn respiratory distress syndrome; NP, neonatal pneumonia; MAS, meconium aspiration syndrome; PS, pulmonary surfactant; INO, inhaled nitric oxide; CRRT, continuous renal replacement therapy.

shorter times than the non-lavage group $(\mathrm{P}<0.05)$. No statistically significant differences were observed among the three groups as regards air leak, pulmonary hemorrhage, patent ductus arteriosus (PDA), bronchopulmonary dysplasia (BPD), intraventricular hemorrhage (IVH), periventricular leukomalacia (PVL), PPHN (P>0.05) (Table II). In addition, no significant differences were found in the OI among the three groups before treatment $(\mathrm{P}>0.05)$. Following treatment, the PS lavage group exhibited a more rapid decline in OI than the NS lavage group, and the PS lavage group and NS lavage group exhibited a more rapid decline in OI decline than the non-lavage group, with the differences being statistically significant $(\mathrm{P}<0.05)$ (Table III).

\section{Discussion}

The age of onset of each disease and diagnostic criteria differ; thus, the inclusion age criteria also differ. The present study examined bronchoalveolar lavage under the ultrasound monitoring of lungs for neonatal atelectasis and lung consolidation. The main subjects of the present study were newborns; thus, the maximum age was 28 days. NRDS presents as aggravated dyspnea caused by the lack of PS, with an onset time with $12 \mathrm{~h}$, particularly within $6 \mathrm{~h}$. Thus, patients with NRDS are younger than $12 \mathrm{~h}$. MAS is more common in full-term infants or post-term infants. The reason for this is that amniotic fluid mixed with meconium is inhaled while the infant is in the uterus or during delivery, and respiratory distress occurs immediately after birth. Another reason is that the chemical inflammation of lung tissue occurs 12-24 h following meconium inhalation. The presence of lung histochemical inflammation can support the diagnosis of MAS. Thus, patients with MAS are younger than $24 \mathrm{~h}$. Neonatal pneumonia is divided into intrauterine infectious pneumonia, infectious pneumonia during childbirth, and postnatal infectious pneumonia. Therefore, the age of neonatal pneumonia patients is no more than 28 days.

Neonatal atelectasis and lung consolidation diseases are often complicated by severe NRDS, severe NP and MAS, which are common causes of dyspnea, difficulty withdrawing and respiratory failure in newborns. The ultrasound imaging of the lungs can be used to monitor these diseases $(1,19,20)$. Invasive mechanical assisted ventilation is used to ensure that 
Table II. Comparison of treatment effects and complications in the three groups.

\begin{tabular}{|c|c|c|c|c|c|}
\hline Group & PS lavage group & NS lavage group & No lavage group & $\mathrm{F} / \chi^{2}$ value & P-value \\
\hline Severe NRDS & 22 & 24 & 27 & & \\
\hline Lung recruitment time (h) & $151.6 \pm 63.8$ & $190.4 \pm 57.5^{\mathrm{a}}$ & $226.1 \pm 60.9^{a, b}$ & 9.1403 & $<0.05$ \\
\hline \multicolumn{6}{|l|}{ Invasive ventilator } \\
\hline healing period (h) & $191.5 \pm 57.7$ & $227.8 \pm 61.4^{\mathrm{a}}$ & $261.8 \pm 56.6^{\mathrm{a}, \mathrm{b}}$ & 8.7539 & $<0.05$ \\
\hline Air leak & 1 & 1 & 2 & 0.31 & $>0.05$ \\
\hline Pulmonary hemorrhage & 1 & 1 & 4 & 2.47 & $>0.05$ \\
\hline PDA & 8 & 7 & 15 & 3.95 & $>0.05$ \\
\hline $\mathrm{BPD}$ & 6 & 6 & 8 & 0.14 & $>0.05$ \\
\hline IVH & 8 & 8 & 12 & 0.72 & $>0.05$ \\
\hline PVL & 7 & 8 & 9 & 0.02 & $>0.05$ \\
\hline Severe NP & 19 & 21 & 20 & & \\
\hline Lung recruitment time $(\mathrm{h})$ & $72.0 \pm 33.6$ & $97.5 \pm 37.5^{\mathrm{a}}$ & $144.4 \pm 35.9^{\mathrm{a}, \mathrm{b}}$ & 20.679 & $<0.05$ \\
\hline \multicolumn{5}{|l|}{ healing period $(\mathrm{h})$} & $<0.05$ \\
\hline Air leak & 1 & 1 & 2 & 0.54 & $>0.05$ \\
\hline Pulmonary hemorrhage & 1 & 1 & 2 & 3.34 & $>0.05$ \\
\hline MAS & 20 & 21 & 24 & & \\
\hline Lung recruitment time (h) & $78.1 \pm 29.6$ & $104.5 \pm 31.5^{\mathrm{a}}$ & $151.4 \pm 32.1^{\mathrm{a}, \mathrm{b}}$ & 31.5377 & $<0.05$ \\
\hline \multicolumn{6}{|l|}{ Invasive ventilator } \\
\hline healing period $(\mathrm{h})$ & $101.2 \pm 28.4$ & $128.7 \pm 30.9^{\mathrm{a}}$ & $179.3 \pm 29.8^{\mathrm{a}, \mathrm{b}}$ & 39.4425 & $<0.05$ \\
\hline Air leak & 2 & 2 & 3 & 0.14 & $>0.05$ \\
\hline Pulmonary hemorrhage & 1 & 1 & 1 & 0.01 & $>0.05$ \\
\hline PPHN & 4 & 4 & 5 & 0.03 & $>0.05$ \\
\hline
\end{tabular}

${ }^{\mathrm{a}} \mathrm{P}<0.05$, compared with the PS lavage group; ${ }^{\mathrm{b}} \mathrm{P}<0.05$, compared with the NS lavage group. NRDS, newborn respiratory distress syndrome; NP, neonatal pneumonia; MAS, meconium aspiration syndrome; PDA, patent ductus arteriosus; BPD, bronchopulmonary dysplasia; IVH, intraventricular hemorrhage; PVL, periventricular leukomalacia; PPHN, persistent pulmonary hypertension of the newborn.

the subject's lung ventilation function is normal, reduce the damage of the oxygen deficit to the body, and withdraw the invasive ventilator after the lungs have re-expanded. Subjects are administered a therapeutic dose of exogenous PS replacement therapy with or no lavage treatment, as severe NRDS, severe NP and MAS can lead to insufficient PS and/or excessive consumption. Exogenous PS replacement therapy can improve lung compliance, stabilize alveolar pressure and can prevent/reduce pulmonary edema. Exogenous PS can also participate in airway immune regulation, which is beneficial to lung disease treatment. Lung ultrasound imaging results have been used to guide whether to use (or reuse) exogenous PS, which can effectively regulate PS application (21-24).

Examination of neonatal atelectasis and lung consolidation diseases with lung ultrasound. The pulmonary ultrasound diagnosis of severe NRDS has a sensitivity of $100 \%$ and a specificity of $99 \%$, with no signs of lag on X-ray chest radiographs $(19,25)$. The pulmonary ultrasound diagnosis of NP has a sensitivity of $100 \%$ and a specificity of $97.2 \%$, and lung ultrasound imaging can detect changes earlier than other imaging and laboratory tests $(9,26)$. The lung ultrasound diagnosis of MAS has a sensitivity of $90.0 \%$ and a specificity of $88.9 \%$. Lung ultrasound has no risk of radiation damage, and can be examined in real-time, which is more suitable for repeated examination than X-ray chest radiography $(2,27)$.

Pulmonary ultrasound and X-ray chest radiography do not reveal any differences in neonatal atelectasis and the positive rate of lung consolidation (26). Lung ultrasound can be used as a routine and preferred method for such diseases $(1,19,25)$. There are research reports that lung ultrasound can also determine the severity and prognosis of the disease from other information outside the lesion range, such as whether the presence of lung pulsation, and whether there is a CDFI blood flow signal in the lesion area $(1,26)$. Therefore, in the present study, lung ultrasound was used for the diagnosis of severe NRDS, severe NP and MAS, as well as in the follow-up of lung recruitment time, the diagnosis of air leak, pulmonary hemorrhage, etc., which is useful for examinations in real-time. It can also reveal changes in the disease, and may thus help adjust the treatment plan, withdraw the machine in time, clarify the complications and treat them in time, and causes no radioactive damage (1) (Table II).

The ultrasonic equipment manually set the ultrasonic propagation velocity to $1,540 \mathrm{~m} / \mathrm{sec}$, and the ultrasonic propagation velocity in the lungs is $440 \mathrm{~m} / \mathrm{sec}$. When there is no pleura-pulmonary disease, the ultrasound is totally reflected and lung examination cannot be performed (9). The ultrasound image of the lungs in this case is defined as normal 
Table III. Comparison of OI among the three groups of children.

\begin{tabular}{|c|c|c|c|c|c|}
\hline Group & PS lavage group & NS lavage group & No lavage group & F value & P-value \\
\hline Severe NRDS & 22 & 24 & 27 & & \\
\hline Before treatment & $24.9 \pm 4.1$ & $24.3 \pm 3.9$ & $24.8 \pm 3.6$ & 0.1651 & $>0.05$ \\
\hline $1 \mathrm{~h}$ & $14.8 \pm 3.7$ & $16.8 \pm 3.8$ & $19.2 \pm 3.4^{\mathrm{a}, \mathrm{b}}$ & 9.0372 & $<0.05$ \\
\hline $12 \mathrm{~h}$ & $10.3 \pm 3.3$ & $13.2 \pm 2.8^{\mathrm{a}}$ & $17.8 \pm 2.5^{\mathrm{a}, \mathrm{b}}$ & 43.2587 & $<0.05$ \\
\hline $24 \mathrm{~h}$ & $7.3 \pm 2.9$ & $9.5 \pm 2.8^{\mathrm{a}}$ & $14.9 \pm 3.6^{\mathrm{a}, \mathrm{b}}$ & 38.5285 & $<0.05$ \\
\hline Severe PN & 19 & 21 & 20 & & \\
\hline Before treatment & $25.3 \pm 3.7$ & $24.9 \pm 3.8$ & $24.7 \pm 3.9$ & 0.1253 & $>0.05$ \\
\hline $1 \mathrm{~h}$ & $16.8 \pm 3.5$ & $16.7 \pm 3.6$ & $19.2 \pm 3.4^{\mathrm{a}, \mathrm{b}}$ & 3.2723 & $<0.05$ \\
\hline $12 \mathrm{~h}$ & $11.7 \pm 3.1$ & $13.7 \pm 2.9^{\mathrm{a}}$ & $16.8 \pm 2.7^{\mathrm{a}, \mathrm{b}}$ & 15.3643 & $<0.05$ \\
\hline $24 \mathrm{~h}$ & $8.1 \pm 3.2$ & $10.1 \pm 2.7^{\mathrm{a}}$ & $14.2 \pm 3.3^{\mathrm{a}, \mathrm{b}}$ & 20.1629 & $<0.05$ \\
\hline MAS & 20 & 21 & 24 & & \\
\hline Before treatment & $26.7 \pm 4.4$ & $26.2 \pm 4.9$ & $26.9 \pm 4.2$ & 0.1412 & $>0.05$ \\
\hline $1 \mathrm{~h}$ & $18.8 \pm 3.1$ & $18.3 \pm 3.6$ & $21.5 \pm 3.4^{\mathrm{a}, \mathrm{b}}$ & 5.9071 & $<0.05$ \\
\hline $12 \mathrm{~h}$ & $12.3 \pm 2.4$ & $14.9 \pm 2.5^{\mathrm{a}}$ & $16.7 \pm 2.3^{\mathrm{a}, \mathrm{b}}$ & 18.4348 & $<0.05$ \\
\hline $24 \mathrm{~h}$ & $7.8 \pm 2.7$ & $10.6 \pm 2.6^{\mathrm{a}}$ & $14.4 \pm 3.0^{\mathrm{a}, \mathrm{b}}$ & 31.2314 & $<0.05$ \\
\hline
\end{tabular}

${ }^{\text {ap }}<0.05$, compared with the PS lavage group; ${ }^{b} \mathrm{P}<0.05$, compared with the NS lavage group. NRDS, newborn respiratory distress syndrome; $\mathrm{NP}$, neonatal pneumonia; MAS, meconium aspiration syndrome.

lung features. At this time, the presence of lesions in lung tissue cannot be detected. When pleura-lung disease occurs, for example, atelectasis and lung consolidation, the air in the alveoli is replaced by non -gas material or the alveoli collapses without air, the ultrasonic propagation speed in the diseased area is similar to that in the soft tissue, and can enter the diseased lung area; thus, the examination can be completed. It can be seen that pleura-pulmonary disease is the basis of lung ultrasound examination. Ultrasound can be used for lung examination, however, based on the aforementioned limitations, when the lung ultrasound image is inconsistent with the clinical manifestation, X-ray chest radiography, CT, MRI and other supplementary examinations are required $(8,28)$.

BAL is effective in treating neonatal atelectasis and lung consolidation. The present study demonstrated that BAL was effective in the treatment of neonatal atelectasis and lung consolidation diseases caused by severe NRDS, severe NP and MAS. BAL treatment decreases the time of lung recruitment and invasive ventilator treatment. PS lavage is superior to NS lavage and does not increase complications (Table II). This was consistent with the findings of previous studies $(11,12,18)$. BAL treatment can wash out foreign bodies and secretions in the airway, can unblock the airway, can help improve the hypoxic state and can also promote alveolar recruitment.

During lavage treatment, transcutaneous oxygen saturation $\left(\mathrm{SpO}_{2}\right)$ of the child should be $>90 \%(29,30)$. The analysis of the effects of BAL (29-34) has revealed the following: i) During the lavage process, the uncomfortable stress response of the child stimulates the body through the hypothalamic-pituitary-adrenal axis to produce glucocorticoids, which exert anti-inflammatory effects, conducive to alveolar recruitment; ii) lavage can reduce inflammation and cytokine levels, and can eliminate certain inflammation and cytotoxic factors, thereby reducing their harm to the body; iii) it can wash out inflammatory exudate, edema fluid, necrotic tissue, etc., which is conducive to alveolar recruitment; iv) lavage fluid from the lavage can be used for smears, stains, and pathogenic examinations to provide a basis for a clear diagnosis and treatment.

BAL treatment can improve OI. The OI is one of the important indicators used to evaluate the effects of respiratory therapy. In the present study, OI was used to evaluate the effect of BAL respiratory therapy in children with severe NRDS, severe NP and MAS $\left(\mathrm{OI}=\mathrm{FiO}_{2} \times \mathrm{MAP} \times 100 / \mathrm{PaO}_{2}\right)$. It integrates the measured parameters of $\mathrm{FiO}_{2}$, MAP and arterial oxygen partial pressure $\left(\mathrm{PaO}_{2}\right)$, avoiding the limitations of single index evaluation. OI directly reflects the degree of respiratory failure and the respiratory treatment effects in children. It is a commonly used parameter in various countries (35). Normally, the OI is $<5$. The OI ranges between 10-15 during respiratory insufficiency, with signs of mechanical ventilation and the OI ranges between 15-20 in respiratory failure. When the OI is $>25-30$, respiratory failure is severe and possibly irreversible; when the OI is $>35-40$, only extracorporeal membrane oxygenation (ECMO) is generally possible. If the OI increases by 5-10 points within a short period of time, this indicates that the condition has sharply deteriorated, and effective intervention measures must be undertaken immediately. Hypoxic respiratory diseases require active treatment to maintain normal oxygenation, the intracellular oxygenation status cannot be directly monitored, Therefore, OI is used clinically to reflect the oxygenation status of the body of the child (36).

The results of the present study demonstrated that following BAL under ultrasound monitoring, the OI rapidly decreased with the prolonged treatment time, and the PS lavage group exhibited a greater decrease compared with the NS lavage group, indicating that BAL treatment was effective 
in improving oxygenation, and was beneficial for improving respiratory function (Table III).

BAL is conducive to unblock the airway; lavage can dilute inflammation and cytotoxic factors, and can lavage out inflammatory exudate, edema fluid, necrotic tissue, etc., which is conducive to alveolar recruitment and clear diagnosis; PS can effectively improve lung compliance and oxygenation, mechanical ventilation can effectively improve ventilation, and the combined application of the three is more effective $(20,29,30,32,33)$.

The present study was prospective study. Severe NRDS, severe NP, and MAS diseases are clinically mainly, dyspnea. The lung ultrasound image reveals atelectasis and lung consolidation. Hence, severe NRDS, severe NP and MAS are considered as a class of imaging diseases. X-ray chest radiographs lead to radioactive damage and these diseases need to be repeatedly monitored. Thus, lung ultrasound technology was innovatively used in real-time in the present study for the dynamic evaluation of whether the lung has been recruited. Moreover, BAL was used in the present study for treatment. In addition to the lung recruitment time and invasive ventilator treatment time, OI is commonly used in international pediatrics, and was also used herein. The aim of the present study was to provide a reference for the clinical application of BAL under the ultrasound monitoring of lungs for the treatment of neonatal atelectasis and lung consolidation diseases. This was a single-center study, and the impact of antibiotics treatment was not evaluated, which poses certain limitations. In the future, the authors aim to conduct a multi-center, large-sample study to also include the impact of antibiotics.

In conclusion, the present study demonstrates that BAL under lung ultrasound monitoring is effective in the treatment of neonatal atelectasis and pulmonary consolidation diseases, that are caused by severe NRDS, severe NP and MAS. It can rapidly decrease the time of neonatal atelectasis, lung consolidation and invasive ventilator treatment, and can also rapidly decrease the OI, without increasing complications. Exogenous PS lavage is also more effective than NS lavage.

\section{Acknowledgements}

The authors would like to thank Kunming Medical University and the Education Department of Yunnan Province for Providing the opportunities required to complete the study and for providing assistance.

\section{Funding}

The present study was supported by the Kunming Medical University and the Education Department of Yunnan Province, China (no. 2019J1316).

\section{Availability of data and materials}

The datasets used and/or analyzed during the current study are available from the corresponding author on reasonable request.

\section{Authors' contributions}

FZ conducted the research design, literature review, data collection, data analysis, and manuscript writing. Both authors (FZ and $\mathrm{YZ}$ ) contributed to the interpretation of the data. YZ participated in data collection. FZ and YZ confirm the authenticity of all the raw data. Both authors have read and approved the final manuscript.

\section{Ethics approval and consent to participate}

The present study was approved by the Medical Ethics Committee of Dehong Hospital Affiliated to Kunming Medical University (Dehongzhou People's Hospital), China, and informed consent was obtained from the guardians of the children.

\section{Patient consent for publication}

Not applicable.

\section{Competing interests}

The authors declare that they have no competing interests.

\section{References}

1. Guideline on lung ultrasound to diagnose pulmonary diseases in newborn infants. Zhongguo Dang Dai Er Ke Za Zhi 21: 105-113, 2019 (In Chinese).

2. Liu J, Cao HY and Fu W: Lung ultrasonography to diagnose meconium aspiration syndrome of the newborn. J Int Med Res 44: 1534-1542, 2016.

3. Sweet DG, Carnielli V, Greisen G, Hallman M, Ozek E, Plavka R, Saugstad OD, Simeoni U, Speer CP, Vento M, et al: European consensus guidelines on the management of respiratory distress syndrome - 2016 update. Neonatology 111: 107-125, 2017.

4. Ping Z, Peng Y, Lang H, Xinyong C, Zhiyi Z, Xiaocheng W, Hong $Z$ and Liang $S$ : Oxidative stress in radiation-induced cardiotoxicity. Oxid Med Cell Longev 2020: 3579143, 2020.

5. Wall BF: Radiation protection dosimetry for diagnostic radiology patients. Radiat Prot Dosimetry 109: 409-419, 2004.

6. Liu J, Cao HY, Wang XL and Xiao LJ: The significance and the necessity of routinely performing lung ultrasound in the neonatal intensive care units. J Matern Fetal Neonatal Med 29: 4025-4030, 2016.

7. Liu J, Liu Y, Wang HW, Li JY, Han T, Liang J, Yang CS, Xing M and Feng ZC: Lung ultrasound for diagnosis of neonatal atelectasis. Zhonghua Er Ke Za Zhi 51: 644-648, 2013 (In Chinese).

8. Kryger M and Kosiak W: Role of lung ultrasound in paediatric patients. Pediatr Med Rodzinna 10: 386-396, 2014.

9. Rea G, Sperandeo M, Di Serafino M, Vallone G and Tomà $\mathrm{P}$ : Neonatal and pediatric thoracic ultrasonography. J Ultrasound 22 : 121-130, 2019.

10. Sharma D and Farahbakhsh N: Role of chest ultrasound in neonatal lung disease: A review of current evidences. J Matern Fetal Neonatal Med 32: 310-316, 2019.

11. Liu J, Liu F, Liu Y, Wang HW and Feng ZC: Lung ultrasonography for the diagnosis of severe pneumonia of the newborn. Chest 146: 483-488, 2014.

12. Liu J, Chen SW, Liu F, Li QP, Kong XY and Feng ZC: The diagnosis of neonatal pulmonary atelectasis using lung ultrasonography. Chest 147: 1013-1019, 2015.

13. Arslan Z, Khurram MA and Sinha MD: Renal replacement therapy and conservative management: NICE guideline (NG 107) October 2018. Arch Dis Child Educ Pract Ed 105: 352-354, 2020.

14. Sethi SK, Mittal A, Nair N, Bagga A, Iyenger A, Ali U, Sinha R, Agarwal I, de Sousa Tavares M, Abeyagunawardena A, et al: Pediatric Continuous Renal Replacement Therapy (PCRRT) expert committee recommendation on prescribing prolonged intermittent renal replacement therapy (PIRRT) in critically ill children. Hemodial Int 24: 237-251, 2020.

15. Trinavarat $\mathrm{P}$ and Riccabona $\mathrm{M}$ : Potential of ultrasound in the pediatric chest. Eur J Radiol 83: 1507-1518, 2014.

16. Chen SW, Zhang MY and Liu J: Application of lung ultrasonography in the diagnosis of childhood lung diseases. Chin Med J Í(Engl) 128: 2672-2678, 2015. 
17. Finer NN and Evans N: Inhaled nitric oxide for the preterm infant: Evidence versus practice. Pediatrics 135: 754-756, 2015.

18. Liu J, Ren XL, Fu W, Liu Y and Xia RM: Bronchoalveolar lavage for the treatment of neonatal pulmonary atelectasis under lung ultrasound monitoring. J Matern Fetal Neonatal Med 30: 2362-2366, 2017.

19. Chen SW, Fu W, Liu J and Wang Y: Routine application of lung ultrasonography in the neonatal intensive care unit. Medicine (Baltimore) 96: e5826, 2017.

20. Sweet DG, Carnielli V, Greisen G, Hallman M, Ozek E, Te Pas A, Plavka R, Roehr CC, Saugstad OD, Simeoni U, et al: European consensus guidelines on the management of respiratory distress syndrome-2019 update. Neonatology 115: 432-450, 2019.

21. Damani J: A challenging case of dyspnea: Acute exogenous lipid pneumonia. Chest 156: A1880, 2019.

22. Baer B, Souza LM, Pimentel AS and Veldhuizen RA: New insights into exogenous surfactant as a carrier of pulmonary therapeutics. Biochem Pharmacol 164: 64-73, 2019.

23. De Luca D, van Kaam AH, Tingay DG, Courtney SE, Danhaive O, Carnielli VP, Zimmermann LJ, Kneyber MC, Tissieres P, Brierley J, et al: The montreux definition of neonatal ards: biological and clinical background behind the description of a new entity. Lancet Respir Med 5: 657-666, 2017.

24. Rodríguez-Fanjul J, Balcells Esponera C, Moreno Hernando J and Sarquella-Brugada G: Lung ultrasound as a tool to guide the administration of surfactant in premature neonates. An Pediatr (Barc) 84: 249-253, 2016 (In Spanish).

25. Liu J, Cao HY, Wang HW and Kong XY: The role of lung ultrasound in diagnosis of respiratory distress syndrome in newborn infants. Iran J Pediatr 25: e323, 2015.

26. Kurepa D, Zaghloul N, Watkins L and Liu J: Neonatal lung ultrasound exam guidelines. J Perinatol 38: 11-22, 2018.

27. Piastra M, Yousef N, Brat R, Manzoni P, Mokhtari M and De Luca D: Lung ultrasound findings in meconium aspiration syndrome. Early Hum Dev 90 (Suppl 2): S41-S43, 2014.

28. Hiles M,Culpan AM, Watts C,Munyombwe T and Wolstenhulme S: Neonatal respiratory distress syndrome: Chest X-ray or lung ultrasound? A systematic review. Ultrasound 25: 80-91, 2017.
29. Liu J, Zhao HR, Wei HL, Chen C, Qiu RX, Ren XL, Zhang L and Gao YQ: Efficacy of bronchoalveolar lavage as adjunct therapy in the treatment of neonatal severe pneumonia: A prospective case-control study. J Trop Pediatr 66: 528-533, 2020.

30. Daniele R: Bronchoalveolar Lavage. Immunology and Immunologic Diseases of the Lung. Year Book Medical Publishers, p705, 1988.

31. Munigala S, Burnham CA, Anderson NW, Liang SY, Lawrence SJ and Warren DK: Diagnostic performance of multiplex nucleic acid testing of bronchoalveolar lavage and bronchial wash specimens for respiratory viral pathogens. J Clin Microbiol 56: e00973-18, 2018.

32. Kamel T, Helms J, Janssen-Langenstein R, Kouatchet A, Guillon A, Bourenne J, Contou D, Guervilly C, Coudroy R, Hoppe MA, et al: Benefit-to-risk balance of bronchoalveolar lavage in the critically ill. A prospective, multicenter cohort study. Intensive Care Med 46: 463-474, 2020.

33. Gharsalli H, Mlika M, Sahnoun I, Maalej S, Douik El Gharbi L and Mezni FE: The utility of bronchoalveolar lavage in the evaluation of interstitial lung diseases: A clinicopathological perspective. Semin Diagn Pathol 35: 280-287, 2018.

34. Barss L, Fraser KL, Kelly MM and Johannson KA: Impact of processing technique on bronchoalveolar lavage cellular analysis. Eur Respir J 51: 1701769, 2018.

35. Muniraman HK, Song AY, Ramanathan R, Fletcher KL, Kibe R, Ding L, Lakshmanan A and Biniwale M: Evaluation of oxygen saturation index compared with oxygenation index in neonates with hypoxemic respiratory failure. JAMA Netw Open 2: e191179, 2019.

36. Hammond BG, Garcia-Filion P, Kang P, Rao MY, Willis BC and Dalton HJ: Identifying an oxygenation index threshold for increased mortality in acute respiratory failure. Respir Care 62: $1249-1254,2017$

This work is licensed under a Creative Commons Attribution-NonCommercial-NoDerivatives 4.0 International (CC BY-NC-ND 4.0) License. 